\title{
Representacions gramaticals i activitat metalingüística dels alumnes de secundària: la categoria verb ${ }^{1}$
}

Carme Duran, Universitat Autònoma de Barcelona

\section{Punt de partida}

\begin{abstract}
Quizá exagero, pero mi impresión es que la gramática se explica mal en el Bachillerato. Los estudiantes de gramática aprenden a etiquetar, no a analizar, a captar la relación que existe entre la forma y el sentido. "Entrevista a Ignacio Bosque: El monje de las palabras" a El País, 2 de maig de 2007.
\end{abstract}

Les investigacions sobre representacions gramaticals (Fisher 1996; Camps et al. 2001, Notario 2001; Durán 2009b) mostren que la manca de reflexió amb què molts alumnes aprenen gramàtica els porta a una barreja de sabers intuïtius i sabers escolars que no els ajuda a sistematitzar els aprenentatges sobre la llengua. Tot i que el nou marc curricular prescriu una aproximació a la gramàtica que parteixi de la reflexió, la realitat és que encara s'ensenya a partir d'una metodologia transmissiva sovint lligada a una concepció de la sintaxi "categorial, dependencial, jeràrquica i recursiva" (Charolles i Combettes 2004) que s'ha traduït moltes vegades en una anàlisi sintàctica basada en les etiquetes de què parla Bosque.

Aquests estudis constaten la necessitat d'un nou enfocament que elabori propostes alternatives per a l'ensenyament de la gramàtica a l'escola i que ajudin a salvar els obstacles amb què es troben els alumnes a l'hora de conceptualitzar els continguts gramaticals (cfr. Fisher 2004; Camps 2007). Es tracta d'obrir nous camins que estableixin una relació entre l'ús i el coneixement reflexiu i sistemàtic de les formes lingüístiques (Camps et al. 2005; Camps i Zayas 2006; Fontich 2006; Milian i Camps 2006) amb l'objectiu de conciliar el desenvolupament de les capacitats verbals i l'adquisició d'uns coneixements sobre la llengua. L'èmfasi es posa, per tant, en la gramàtica explícita, fruit no de la transmissió de coneixements sinó de la reflexió. Són propostes basades en el paper actiu de l'alumne i en un canvi de rol del professorat, que passa a tenir un paper de bastida i guia d'aquest procés $^{2}$.

És en aquest marc on situem aquesta recerca sobre el concepte de verb dels alumnes de secundària, amb la finalitat d'indagar en la manera que els nois i les noies construeixen el seu coneixement sobre el sistema lingüístic, com un primer pas per, 
d'una banda, entendre com es produeix el procés d'interiorització dels coneixements gramaticals, i d'una altra, poder dissenyar dispositius didàctics més eficaços, a través d'una metodologia d'ensenyament gramatical basada en el diàleg que permeti la reflexió sobre la llengua. Concretament ens proposem els objectius següents:

a) observar de quina manera els estudiants construeixen la representació de la categoria verb;

b) analitzar la representació que tenen sobre aquesta categoria per tal de detectar les dificultats amb què es troben a l'hora de categoritzar-la, $\mathrm{i}$

c) comprovar de quina manera fan operativa la definició en tasques d'identificació.

\section{Marc de la recerca}

Els referents teòrics d'aquesta investigació es poden agrupar en tres: a) els estudis sobre les nocions gramaticals que els alumnes construeixen a partir de fonts diverses; b) els obstacles epistemològics de la pròpia disciplina, és a dir, la complexitat del verb i les dificultats que els alumnes troben a l'hora de conceptualitzar-lo; i c) les aportacions que se centren en l'activitat metalingüística i la interiorització dels sabers gramaticals.

\section{a)Les representacions gramaticals dels estudiants}

Els estudis sobre representacions en relació a un objecte de saber tenen com a base les teories constructivistes i socioconstructivistes segons les quals els alumnes construeixen activament el coneixement a partir de l'experiència prèvia $\mathrm{i}$ de la interacció amb els altres (Coll et al. 1993). La construcció es fa a través del que s'ha anomenat representacions, és a dir, el conjunt relativament organitzat de coneixements i concepcions que tenen els alumnes sobre qualsevol tema i que poden servir tant per integrar la nova informació com per interferir-hi fins al punt de convertir-se en un obstacle per a l'apropiació dels nou sabers (Fisher 1996 i 2004; Notario 2001). Aquestes representacions no són estàtiques, sinó que es modifiquen, es van revisant i es tornen més complexes. Qualsevol nou aprenentatge haurà de construir-se des dels esquemes existents cosa que comporta la caracterització dels coneixements previs com a punt de partida per a nous aprenentatges.

En aquests estudis, s'hi constata la diferència entre els sabers ensenyats i el que els alumnes s'apropien, i el progrés del coneixement s'entén més aviat com un procés de construcció/deconstrucció en el qual les concepcions i els coneixements anteriors 
juguen un paper fonamental. L'estudi de les representacions condueix d'aquesta manera a la voluntat de salvar els obstacles i a definir les condicions didàctiques per aconseguir-ho com mostra la figura 1 (Fisher 2004:389).

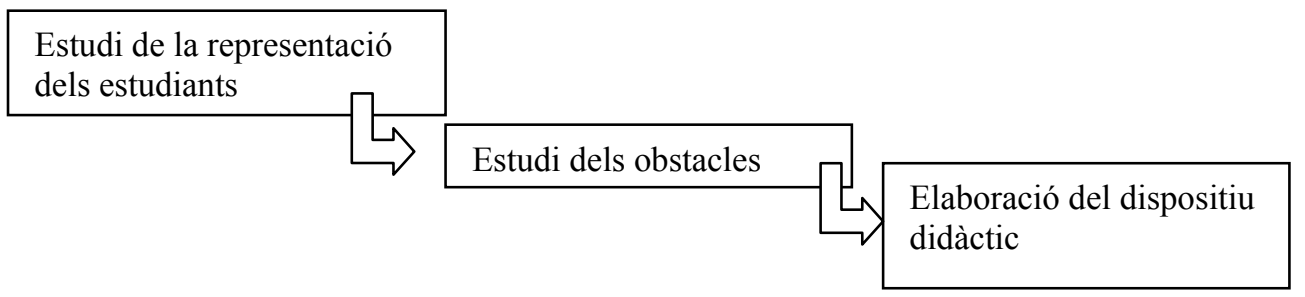

Figura 1: Representacions de l'acció didàctica (Fisher, 2004:389)

Les recerques precedents sobre els conceptes gramaticals dels escolars (Brossard i Lambelin 1985, sobre els conceptes de subjecte, verb i complements; Kilcher, OtheninGirard i de Weck 1987, sobre els conceptes de nom, adjectiu, i complement directe; Fisher 1996, sobre la categoria adjectiu; Camps 2000a i Camps et al. 2001, sobre la categoria pronom personal; Notario 2001, sobre la noció de subjecte; Durán 2009b i Fittipaldi en premsa, sobre la categoria adverbi, entre d'altres) insisteixen en la necessitat de tenir-los en compte en les situacions d'ensenyament i aprenentatge, sobretot per transformar-los amb els mitjans apropiats. Es tracta de comprendre la manera en què els alumnes aprenen les nocions gramaticals i, si és possible, veure com evolucionen aquests sabers.

Algunes idees que es desprenen d'aquestes investigacions són les següents:

- es detecta una falta de coherència i de sistematització en els sabers gramaticals que han elaborat els alumnes;

- els seus sabers apareixen com un conglomerat de coneixements procedents de diverses fonts, en una barreja d'aspectes tant formals com funcionals $o$ semàntics, sovint desconnectats entre si (Fisher 1996; Camps i altres 2001; Durán, 2009b);

- l'ús de diversos criteris (formal, funcional i semàntic) de forma combinada ajuda a construir la comprensió global de la noció (Brossard i Lambelin 1985);

- els conceptes poden quedar fossilitzats (Notario 2001) i es converteixen en un obstacle per als nous aprenentatges;

- el pes de l'exemple paradigmàtic es converteix per a l'alumne en el punt de referència (Notario 2001); 
- es constata una separació entre sabers declaratius i sabers procedimentals (Notario 2001; Camps i altres 2001);

- l'entrevista es mostra com a instrument per fer emergir els sabers dels alumnes, però també com a eina d'aprenentatge (Camps i altres 2001);

- el diàleg reflexiu es mostra fonamental com a eina d'aprenentatge i de regulació del pensament (Durán 2009b)

\section{b) Les dificultats epistemològiques de la categoria verb}

Per entendre els obstacles amb què es troben els alumnes en la construcció de la noció gramatical, cal tenir en compte la dificultat intrínseca dels sabers gramaticals (Fisher 1996 i 2004; Camps 2007), mancats a l'escola d'uns referents teòrics clars. D'aquesta complexitat, n'és un exemple la dificultat de definir i delimitar les categories i que ja està en el si de la pròpia gramàtica: barreja de criteris en les definicions, indistinció entre llengua i realitat extralingüística, confusió entre categoria i funció, dificultat de saber si un determinat comportament gramatical correspon a una categoria o a una altra, etc. L'escola no només no ha resolt aquests problemes, sinó que, a més, provoca una profunda paradoxa: d'una banda, intenta fer senzilla la complexitat, amb la necessitat de simplificar continguts gramaticals molt complexos perquè els alumnes se'ls puguin apropiar, però, alhora, aquesta mateixa simplificació crea dificultats i obstacles per entendre la complexitat.

El verb és una de les nocions que presenta major dificultat epistemològica. Considerat com a una de les categories bàsiques per les diferents gramàtiques, cadascuna la defineix des d'enfocaments diferents. No intentarem fer un tractament exhaustiu del tema, perquè no és l'objectiu de la nostra recerca, però conèixer la complexitat de la categoria permet entendre d'on provenen les dificultats amb què es troben els alumnes a l'hora de conceptualitzar-la. Amb aquesta finalitat, farem un repàs molt sintètic dels aspectes que s'utilitzen tradicionalment per definir el verb:

- Des d'un punt de vista funcional o sintàctic, és el nucli del SV i nucli, per tant, del predicat. Es tracta d'una funció privativa, tot i que algunes gramàtiques parlen d'elements nominals que poden funcionar com a nuclis del predicat. Segons la naturalesa del lexema verbal, els verbs poden anar sols o poden ser necessaris altres constituents que atorguin una complementació semàntica. 
- Des d'un punt de vista morfològic o formal, és aquell lexema capaç de combinar-se amb morfemes de nombre, aspecte, mode, temps i persona. A més de persona i nombre, els verbs poden concordar en gènere (en el cas del participi) amb alguns dels seus arguments. És a dir, que és una categoria variable quant a la concordança (persona i nombre) i quant a la temporalitat (temps, aspecte i mode). Molts lingüistes coincideixen que són precisament els trets morfològics els que el defineixen millor i que la concordança verbal és l'única realment distintiva i general per a tota la categoria.

- Des d'un punt de vista semàntic o del significat, el verb se sol considerar una classe de significat ple (tot i que aquesta característica no defineix tots els tipus de verbs); presenta unes característiques semàntiques relacionades amb els valors $+/$ - predicatiu $\mathrm{i}+/$ - transitiu. Els verbs transitius determinen el seu significat per la capacitat de prescindir o no del complement directe. Ara bé, la transitivitat pot ser entesa com una funció semàntica, ja que delimita el contingut del verb, però també sintàctica, perquè es relaciona amb el fet que el verb vagi acompanyat d'un argument. Per això alguns autors (Hernanz i Brucart, 1987; citats a Cuenca, 1996) defensen que la transitivitat no és una característica del verb, sinó de l'estructura del sintagma verbal.

La separació de criteris per definir el verb, tot i ser necessària per abordar una explicació gramatical a l'aula, mostra una dels obstacles amb què es troben els estudiants: la dificultat de separar el tres plans, que s'interrelacionen i apareixen com un tot indissoluble. Aquesta combinació de criteris és la que ajuda l'expert a entendre correctament la complexitat de la categoria, però òbviament dificulta la conceptualització per part dels aprenents, que han de crear estratègies per saber-los utilitzar en cada situació.

\section{c) L'activitat metalingüística i l'apropiació dels coneixements gramaticals}

Partim de la hipòtesi que l'ensenyament $\mathrm{i}$ aprenentatge de la gramàtica ha de sustentarse en un coneixement que promogui la reflexió sobre el funcionament de la llengua de manera que permeti “establecer puentes entre el conocimiento intuitivo, implícito, manipulativo, verbalizado con las palabras de cada día, y el conocimiento sistematizado sobre la lengua y sus usos" (Milian i Camps 2006:27). En aquesta línia, alguns investigadors (cfr. Camps, Milian, Zayas, Fontich) centren l'atenció en l'activitat metalingüística dels estudiants i el seu paper en l'apropiació dels aprenentatges 
gramaticals. Amb aquest terme -activitat metalingüística- es fa referència al coneixement sobre la llengua i la manifestació, conscient o inconscient, d'aquest coneixement (Camps i altres 2005; Milian i Camps 2006). Destaquem les investigacions iniciades pel grup GREAL ${ }^{3}$ a partir de la constatació que els alumnes, quan escriuen en col-laboració, porten a terme una intensa activitat que els porta a reflexionar sobre el sistema lingüístic (Camps i Milian 2000; Camps, Guasch, Milian i Ribas 2000). Com assenyala Camps (2000b), aquesta activitat pot aparèixer de manera implícita (en forma de regulació d'un text oral o escrit, per exemple) o de manera explícita a través de l'ajuda del llenguatge comú o del metallenguatge. L'estudi de les característiques d'aquesta activitat n'ha permès establir diferents categories (Camps i Milian 2000; Camps 2007): no conscient, conscient, verbalitzada amb un llenguatge comú o a través d'un metallenguatge específic. És a dir, que s'hi pot observar l'existència de diferents nivells de consciència i d'explicitació de l'activitat metalingüística.

Aquesta emergeix a través de la interacció entre iguals i amb l'expert, i és amb el diàleg amb els altres quan l'individu posa en marxa mecanismes autoreguladors a través de tasques d'alta dificultat cognitiva, com la planificació o la resolució de problemes (Vigotski, 1988). És a dir, que el domini del sistema lingüístic permet regular els intercanvis socials, però també controlar la pròpia conducta, de manera que s'arribi a una apropiació dels continguts i, per tant, a una aprenentatge (Lantolf, 2000). Aquesta apropiació o interiorització de l'objecte de saber es fa a través del que anomena llengua privada (private speech) que té una funció psicològica i estratègica: representa una exteriorització de les ordres internes com a manera de tenir el control de les funcions cognitives per portar a terme la tasca, una funció similar a la de la llengua social en la regulació externa. La verbalització permet observar les accions que van de l'intramental a l'intermental; és a dir, permet fer visible la llengua interior (Wertsch, 1885; citat a Lantolf i Appel, 1994); permet, en definitiva, tenir evidències observables de l'activitat metalingüística del parlant.

\section{La investigació}

Es tracta d'un estudi exploratori per la qual cosa la metodologia utilitzada ha estat diversa. Partint del model de Camps et al. (2001), vam seguir aquesta estructura:

a) Una prova amb dos exercicis: un d'identificació del verb i reconeixement del temps verbal i un altre de definició de la categoria amb què es pretenia fer emergir 
algun tipus de coneixement declaratiu. Les dues activitats es van dissenyar d'acord amb els dos objectius principals de la investigació: saber fins a quin punt els alumnes són capaços de definir/caracteritzar el concepte de verb i comprovar de quina manera ho fan operatiu.

b) Entrevistes semiestructurades a onze estudiants, elaborades a partir d'un petit guió previ (vegeu figura 2) amb la finalitat d'observar com reflexionen i com intenten explicar el que saben, quin tipus de metallenguatge fan servir, quines són les dificultats que expliciten o què hi ha de gramàtica intuïtiva $\mathrm{i}$ de gramàtica conscient en les seves observacions.

\begin{tabular}{|c|c|}
\hline Identificació del verb & $\begin{array}{l}\text { - Verb correctament identificat } \\
\text { - Verbs o part del verb que no han estat } \\
\text { identificats } \\
\text { - Paraula identificada com a verb erròniament }\end{array}$ \\
\hline $\begin{array}{l}\text { Reconeixement del temps } \\
\text { verbal }\end{array}$ & $\begin{array}{l}\text { - Les formes no personals } \\
\text { - Formes personals } \\
\text { - Distinció simple / compost } \\
\text { - Valors del diferents tipus de passat }\end{array}$ \\
\hline Definició del verb & $\begin{array}{l}\text { - Indica acció } \\
\text { - Expressa temps } \\
\text { - La concordança verbal }\end{array}$ \\
\hline
\end{tabular}

Figura 2: Esquema de continguts de l'entrevista

L'estudi es va dur a terme el curs 2007-08 a un institut de la comarca del Garraf (Barcelona) durant el primer trimestre de curs. La prova es va passar a tres grups heterogenis de 4t d'ESO (N1=19, N2=19 i N3=18) a l'assignatura de Llengua i literatura castellana, de manera que les dades ens permetessin indagar en les representacions que els nois i les noies havien construït al llarg de tota l'escolarització i veure'n el resultat en finalitzar l'etapa d'educació obligatòria. Es va passar a l'aula ordinària, a l'hora de classe, $\mathrm{i}$ van ser presents en tot moment la investigadora $\mathrm{i}$ el professor. Les entrevistes es van fer individualment fora de l'aula ordinària $i$ es van enregistrar en una gravadora d'àudio uns dies després.

Els procediments i instruments d'anàlisi han estat diversos, tenint en compte el que es pretenia de cadascuna de les activitats $\mathrm{i}$ del tipus de dades que aporten unes $\mathrm{i}$ altres. Tant les de resposta més tancada (identificació del verb i reconeixement del temps al qual pertanyen) com les de resposta oberta (definició de verb) han estat tractades informàticament. En aquest últim cas, les dades han estat sotmeses a un procés de categorització per tal de fer-ne l'anàlisi posterior. Les dades quantitatives extretes a través d'aquests mètodes informàtics ens han permès albirar alguns dels aspectes clau 
en la representació que s'han fet els alumnes de la categoria, tot i que era necessari contrastar aquestes dades amb altres instruments d'anàlisi.

En el cas de les entrevistes, també hem seguit un doble procés de transcripció $^{4} \mathrm{i}$ posterior categorització de les respostes dels entrevistats. La gran heterogeneïtat de criteris que fan servir els alumnes i els diferents graus d'adequació al llenguatge metalingüístic, tant en les respostes escrites com les orals, fa que la categorització sigui complexa i dificulta l'anàlisi del discurs metalingüístic dels alumnes, en què es donen diferents nivell d'abstracció i de reflexió.

\section{Anàlisi de les dades i comentari dels resultats}

a) Identificació del verb i reconeixement del temps verbal

De l'anàlisi de les dades, se'n desprèn que els alumnes majoritàriament reconeixen aquesta categoria gramatical $^{5}$ (vegeu la figura 3). Les que presenten menys encerts són les formes no personals, especialment el gerundi i el participi, formes que, d'altra banda, presenten una gran dificultat epistemològica ${ }^{6}$.

\begin{tabular}{|l|c|c|}
\hline \multicolumn{1}{|c|}{ Forma verbal } & el reconeixen & $\begin{array}{c}\text { no el } \\
\text { reconeixen }\end{array}$ \\
\hline Infinitivo & $81 \%$ & $19 \%$ \\
\hline Gerundio & $68 \%$ & $32 \%$ \\
\hline Participio & $16 \%$ & $84 \%$ \\
\hline Presente & $71 \%$ & $29 \%$ \\
\hline Pretérito imperfecto & $74 \%$ & $26 \%$ \\
\hline Pret. indefinido (o perfecto simple) & $79 \%$ & $21 \%$ \\
\hline Pret. perfecto (compuesto) & & $17 \%$ \\
\hline Pret. pluscuamperfecto & $83 \%$ & $18 \%$ \\
\hline Imperativo & $82 \%$ & $26 \%$ \\
\hline MITJANA & $74 \%$ & $26 \%$ \\
\hline
\end{tabular}

Figura 3: Reconeixement dels temps verbal del text

Confonen poques paraules amb un verb (només el 6,9\%), cosa que ens permet intuir algunes de les estratègies que fan servir per identificar la categoria: la definició nocional de verb com a paraula que indica acció (per exemple, un 10,6\% dels alumnes subratlla com a ver el sintagma hacer la compra; o un $21 \%$ identifica com a verb el substantiu amenaza), l'atenció a la forma (les terminacions en -er relacionades amb l'infinitiu, com 
mercader) o la poca importància que atorguen al context ${ }^{7}$, amb la confusió de paraules homònimes d'altres categories.

Identifiquen amb molta seguretat els verbs en les seves formes simples, però comencen els problemes quan aborden les formes compostes, ja que el 24\% dels alumnes no reconeix l'auxiliar o el participi ${ }^{8}$. En el cas de formes complexes com les perífrasis verbals o els verbs pronominals, el que preval és l'estructura, no la relació sintàctica entre els elements. Per exemple, en el cas de l'estructura pronom + verb no fan cap distinció a l'hora d'identificar el pronom com a part del verb (els percentatges són similars tant si es tracta d'un verb pronominal com si no).

Han construït, per tant, una representació del verb que els permet la identificació amb d'èxit; en canvi, mostren grans dificultat a l'hora de concretar el temps al qual pertanyen les formes verbals. Aquesta dificultat s'expressa de diverses maneres: d'una banda, alguns estudiants no indiquen a quin temps pertany el verb tot $\mathrm{i}$ que l'identifiquen correctament (vegeu la figura 4); d'una altra, la majoria dels qui intenten alguna resposta només fan una classificació temporal bàsica entre passat, present i futur. Són pocs els alumnes que arriben a una major precisió.

\begin{tabular}{|c|lc|}
\hline No identifiquen el verb & $26 \%$ & \\
\hline Identifiquen el verb & $74 \%$ & $45 \%$ \\
o Només els subratllen & & $29 \%$ \\
$0 \quad$ Els subratllen i en diuen & & \\
alguna cosa & \\
\hline
\end{tabular}

Figura 4: Identificació i reconeixement del temps verbal

No saben situar les formes no personals del verb dintre del paradigma verbal: només un de cada deu alumne reconeix i identifica correctament l'infinitiu; un de cada sis, el gerundi; i ningú, el participi. No sabem si això és degut a un problema terminològic -no saben el nom de la forma verbal- o bé senzillament mostren un intent de col-locar-los en un paradigma temporal (relacionant implícitament verb amb valor de temps) ${ }^{9}$. De les formes personals, el temps que identifica un percentatge més alt d'alumnes és el present (17\% dels alumnes), mentre que les que presenten major dificultat són el pretérito perfecto (només 1'1\% dels alumnes) i el pretérito perfecto compuesto (el 3\%). Les respostes van des d'aquelles que només indiquen que es tracta d'un passat, passant per aquelles que es fixen en la forma simple/compost, fins a les que aventuren ja un nom 
concret de la forma verbal. Això ens permet inferir que els alumnes presenten dificultats per saber de quin temps es tracta perquè no entenen els matisos que aporten els diferents temps i perquè el propi terme no ajuda a resoldre'ls.

Una altra dificultat ve donada per la confusió entre el temps cronològic i el temps gramatical, ja que la qüestió de la temporalitat té a veure amb l'acte de l'enunciació i amb la distribució temporal que s'hi fa. Per exemple, els usos i valors del perfet són nombrosos com a conseqüència de la complexitat de les seves propietats aspectuals. Aquest fet es pot veure en la dificultat que els suposa el pretérito perfecto, un temps verbal molt complex, perquè el seu valor de significació té estretes relacions tant amb el present com amb el pretèrit. D'aquí la confusió d'alguns alumnes, que sembla que apliquin un criteri de significació per dir que és un present (una de cada quatre respostes).

\section{b) Definició de la categoria}

La segona part de l'activitat tenia com a objectiu fer emergir el coneixement declaratiu. L'anàlisi de les respostes mostra que els alumnes saben moltes coses sobre aquesta categoria: fan referència a molts aspectes formals, sintàctics i semàntics. Ara bé, es tracta de definicions fetes per acumulació, sense cap tipus d'ordre aparent, sovint basades en oposicions de binomis com regular / irregular, personal / no personal, etc., com podem veure a la figura 5.

\begin{tabular}{|l|r|}
\hline Definició & Arguments \\
\hline (A2) El verbo es una palabra que expresa una acción. El verbo & significat d'acció \\
tiene género y número. Los verbos se clasifican en muchos & gembre \\
grupos según su estructura. Hay verbos regulares e irregulares, & regulars/irregulars \\
también copulativos (ser, estar, parecer) y predicativos. El & copulatius/predicatius \\
verbo hace de predicado en una oración y de núcleo en el & nucli del predicat i del SV \\
sintagma verbal. El verbo puede ir acompañado de adverbios & acompanyants: l'adverbi \\
(que le dan una característica, y una persona (yo, tú, él, etc...). & persona \\
El verbo puede ser gerundio, participio, infinitivo. Y tiene tres & formes no personals \\
conjugaciones 1r (acabados en -ar), 2n (acabados en -er o-re) & models de conjugacions \\
y 3r (acabados en -ir). & \\
\hline
\end{tabular}

Figura 5: Definició de verb (A2)

La gran complexitat del concepte fa que no tinguin clares les fronteres entre uns plans i altres. La resposta dels alumnes és un mena de calaix de sastre on hi cap tot allò que els 
sona, en una barreja de criteris que intenten atendre tant a la forma, com a la funció, com al significat. Com ja hem vist aquesta dificultat ja ve donada per la pròpia forma del verb: els morfemes aporten molta informació, però d'una manera indissoluble, difícil de delimitar.

En general preval el criteri semàntic per sobre dels altres, ja que és el que utilitzen més alumnes (i sempre iniciant la definició, la qual cosa indica la rellevància que té per a ells aquest criteri), però també és cert que li dediquen pocs arguments: bàsicament associen el verb amb un significat d'acció. En canvi, és el criteri formal el que aporta més arguments com reflecteix la figura 6; és a dir, que els alumnes mostren un coneixement ampli de les característiques morfològiques del verb.

\begin{tabular}{|l|l|l|l|l|l|l|}
\hline & \multicolumn{2}{|l|}{ Criteri semàntic } & \multicolumn{2}{l|}{ Criteri sintàctic } & \multicolumn{2}{l|}{ Criteri morfològic } \\
\cline { 2 - 7 } & freqüència & $\%$ & freqüència & $\%$ & freqüència & $\%$ \\
\hline Arguments & 32 & $32 \%$ & 12 & $12 \%$ & 56 & $56 \%$ \\
\hline Alumnes & 29 & $76 \%$ & 8 & $21 \%$ & 21 & $55 \%$ \\
\hline
\end{tabular}

Figura 6: Criteris utilitzats en la definició

Sorprèn, en canvi, que, tot i que moltes vegades l'estudi de les categories es planteja a les aules com un primer pas a l'anàlisi sintàctica, el criteri funcional és el menys utilitzat, tant per nombre d'alumnes (només un de cada cinc alumnes) com per nombre d'arguments (un 12\% del total).

Les definicions deixen entreveure un vocabulari molt escolar que sembla més fruit de la memorització que de l'apropiació dels coneixements (expresan acción, estado o proceso; acepta morfemas de tiempo...). D'altra banda, mostren una gran dificultat a l'hora de trobar les paraules adequades per parlar de la llengua. Pensem que el poc domini de la terminologia específica els fa més difícil elevar el grau d'abstracció; és a dir, que el fet de no posseir un ús adequat del llenguatge específic els impedeix apropiar-se correctament del coneixement metalingüístic ${ }^{10}$. Tot i això, cal dir que les respostes mostren diferències entre els alumnes en la utilització de la terminologia específica, des d'aquelles que intenten un llenguatge metalingüístic més ajustat a l'explicació gramatical i un elevat grau d'abstracció ((6) nos explica la acción que 
realiza el sujeto; (36) se caracteriza por ser una acción que realiza alguien, a veces el sujeto, otras el $C D$ ), fins a les que no fan distinció entre llengua i realitat i fan servir un llenguatge comú ((9) el verbo es lo que está haciendo una persona o animal; (10) el verbo es un gesto o movimiento de una determinada cosa).

D'entre les estratègies que utilitzen per identificar la categoria, la més utilitzada és conjugar-lo, posant sempre al davant el pronom personal en funció de subjecte. Sembla que els alumnes hi detecten una relació pleonàsmica que els ajuda a entendre el valor morfològic i semàntic dels morfemes de persona i nombre. En la seva representació de la categoria, la concordança verbal en particular i els trets morfològics en general són els que els defineixen millor. Altres estratègies, com en el cas de la distinció entre verbs copulatius i verbs predicatius, ens fa plantejar que poden ser, alhora, ajudes per sistematitzar el concepte o obstacles que en dificulten la reflexió. Així, saber-se els verbs copulatius de manera memorística i automatizada (ser, estar y parecer, sempre citats en el mateix ordre pels alumnes en les seves definicions) com qui se sap la llista de les preposicions, pot ser molt útil en un primer estadi de reconeixement de les categories, però, si no es dóna un pas en què es tinguin en compte l'ús i el sentit del context, aquesta mateixa estratègia es pot convertir en un obstacle per a la reflexió, ja que impedeix considerar altres verbs com a possibles copulatius (el que alguns lingüistes anomenen semiatributius) o bé no adonar-se que hi ha contextos d'ús en què els mateixos verbs citats funcionen com a predicatius.

\section{c) Relacions entre els sabers declaratius i els sabers procedimentals}

En el contrast entre el que diuen sobre el verb i el que fan per identificar-lo, el primer que constatem és que els alumnes responen a les dues activitats de manera diferent. En la primera, veiem que posen en joc estratègies per identificar la categoria que els són molt útils, perquè cometen pocs errors. No passa el mateix amb el reconeixement del temps verbal, perquè no sembla que tinguin prou eines per arribar a una solució reeixida: els fallen els termes, no entenen els valors que aporta cada temps verbal a partir del nom. En la segona activitat, en què apareixen els sabers declaratius sobre el verb, el que fan és abocar tot el que els sona, d'una manera inconnexa i desorganitzada, com si verbalitzessin un coneixement escolar memoritzat al llarg dels anys. Ara bé, tot i aquest "desordre" i la confusió entre alguns conceptes, el que veiem és que els sonen molts aspectes sobre el verb: han construït una bastida amb molts pisos per fer-se la 
representació de la categoria. El problema és que la bastida no sembla sustentar-se sobre fonaments sòlids.

Detectem, per tant, una clara separació entre els sabers declaratius (bàsicament memorístics i inconnexos; sabers que han estat construïts a partir de l'acumulació, però no de la reflexió) i uns sabers procedimentals, que a vegades semblen aplicats mecànicament, però que responen a l'ús d'unes estratègies que els són molt útils per identificar la categoria, estratègies que, creiem, han sorgit de la representació que han anat construint al llarg dels anys d'escolarització i que cada vegada s'ha fet més complexa.

\section{d) Les entrevistes}

Les característiques del gènere possibiliten la creació d'un espai de reflexió en què els alumnes poden prendre el seu temps per explicitar allò que saben i mostren alguns moments de l'activitat metalingüística que es porta a terme davant les preguntes de l'entrevistadora que van guiant la reflexió. L'entrevista es converteix en un instrument metodològic molt útil per intentar captar aquest procés de categorització, sovint invisible per al docent per la pròpia dinàmica de les classes $i$, alhora, en un instrument d'aprenentatge.

L'anàlisi de la conversa entre els estudiants i la investigadora ens permet afirmar que és en la interacció quan els estudiants es posen en situació d'observar la llengua com a objecte d'estudi. Les preguntes suposen un repte cognitiu que fa emergir l'activitat metalingüística dels estudiants, moment en què podem observar les diferents estratègies que els alumnes utilitzen per categoritzar el verb. Però també mostren les confusions, els dubtes, els moments de fricció entre el que s'ha après de una manera memorística i la reflexió a partir d'exemples concrets.

Ens centrarem en un dels aspectes tractats a les entrevistes ${ }^{11}$ : la noció de verb com a paraula que indica acció, definició que sembla que ha quedat fossilitzada en el saber declaratiu dels escolars. Aquesta seqüència (figura 7, tons 1-25) permet veure, d'una banda el pes de les definicions escolars automatitzades en l'argumentació de l'alumna, i d'una altra com les estratègies de reconeixement $-\mathrm{i}$ per tant els sabers procedimentalsno van directament relacionades amb els sabers declaratius.

\begin{tabular}{|l|l|l|}
\hline TORN & \multicolumn{1}{|c|}{ ENTREVISTADORA } & MARIA \\
\hline 1 & $\begin{array}{l}\text { (..) dices que nos explica: que el verbo } \\
\text { nos explica la acción que realiza el } \\
\text { sujeto } \downarrow \text { lo podrías explicar un poquito }\end{array}$ & \\
\hline
\end{tabular}




\begin{tabular}{|c|c|c|}
\hline & más $\uparrow$ & \\
\hline 4 & & $\begin{array}{l}\text { pues significa que es lo que está haciendo el } \\
\text { sujeto en aquel momento } \downarrow \text { que: que o sea- } \\
\text { pues si está parado es que está parado si } \\
\text { camina pues que camina } \downarrow \text { todo lo que está } \\
\text { haciendo el sujeto } \downarrow\end{array}$ \\
\hline 5 & $\begin{array}{l}\operatorname{mhm} \downarrow \text { y: en el caso- en el caso de este } \\
\text { verbo que me has subrayado érase } \uparrow \text { qué } \\
\text { tipo de acción está realizando } \uparrow\end{array}$ & \\
\hline 6 & & $\begin{array}{l}\text { m: ser existir supongo } \uparrow \text { porque: a ver se } \\
\text { supone que todo el mundo existe no } \uparrow \text { pero: a } \\
\text { lo mejor para remarcarlo más pues se pone el } \\
\text { verbo dentro } \downarrow\end{array}$ \\
\hline 7 & $\begin{array}{l}\text { por lo tanto el verbo: en este caso el } \\
\text { verbo es una acción } \downarrow \text { indica una acción } \downarrow\end{array}$ & \\
\hline 8 & & sí $\downarrow$ \\
\hline 9 & $\begin{array}{l}\text { y: en el caso de esta noche quiero } \uparrow \text { quiero } \\
\text { estar } \uparrow \text { este verbo que verbo sería el verbo } \\
\text { quiero }\end{array}$ & \\
\hline 10 & & querer $\downarrow$ \\
\hline 11 & querer $\downarrow$ y querer es una acción $\uparrow$ & \\
\hline 12 & & sí $\downarrow$ \\
\hline \multicolumn{3}{|c|}{$(\ldots)$} \\
\hline 15 & indica que haces algo $\uparrow$ & \\
\hline 16 & & $\begin{array}{l}\text { indica que quieres algo } \downarrow \text { a lo mejor a veces } \\
\text { es una acción involuntaria pero es una } \\
\text { acción } \downarrow\end{array}$ \\
\hline 17 & $\begin{array}{l}\text { mhm } \downarrow \text { y: sorprenderse } \uparrow \text { en el caso de me } \\
\text { ha sorprendido verlo aquí } \uparrow\end{array}$ & \\
\hline 18 & & $\begin{array}{l}\text { sí } \downarrow \text { bueno es una: reacción pero sí } \downarrow \text { es una } \\
\text { acción que hace } \downarrow\end{array}$ \\
\hline 19 & $\operatorname{mhm} \downarrow$ y amenaza $\uparrow$ es una acción $\uparrow$ & \\
\hline 20 & & $\begin{array}{l}\text { supongo } \downarrow \text { a ver } \downarrow \text { m: sí pero: es como: una } \\
\text { ayuda al verbo o sea en este caso ha hecho } \\
\text { un gesto de amenaza un gesto de amenaza es } \\
\text { para describir que es lo que ha hecho } \downarrow \text { no } \uparrow \\
\text { supongo }\end{array}$ \\
\hline 21 & $\begin{array}{l}\text { y entonces la amenaza es una acción en } \\
\text { este caso } \uparrow\end{array}$ & \\
\hline 22 & & sí $\downarrow$ \\
\hline 23 & y por lo tanto sería un verbo o no $\uparrow$ & \\
\hline 24 & & no $\downarrow$ porque acompaña al verbo ha hecho \\
\hline 25 & $\begin{array}{l}\text { porque para que sea un verbo: cómo los } \\
\text { distingues } \uparrow \text { para saber por ejemplo que } \\
\text { amenaza no es un verbo y en cambio ha } \\
\text { sorprendido sí }\end{array}$ & \\
\hline 26 & & $\begin{array}{l}\text { pues: los pongos en: en el- en el- en } \\
\text { infinitivo } \downarrow \text { así puedo pasarlos al infinitivo y } \\
\text { depende de donde estén del contexto }\end{array}$ \\
\hline
\end{tabular}

Figura 7: Seqüència: definició del verb com a paraula que indica acció (María)

L'entrevistadora llegeix a l'alumna la definició que ha escrit sobre el verb com a agent de l'acció ("el verbo nos explica la acción que realiza el sujeto") i li demana que ho justifiqui. Es tracta, per tant, d'una definició feta des d'un enfocament semàntic, però 
molt restrictiva, perquè deixa fora els verbs que no són d'acció. L'alumna dóna una explicació gairebé tautològica en què, a més, incorpora la idea de temporalitat (torn 4: "pues significa que es lo que está haciendo el sujeto en aquel momento"). L'entrevistadora la posa en situació de contrastar la definició amb verbs que no són d'acció (érase, quiero, ha sorprendido) i l'alumna s'agafa a la definició com a una

fórmula. És a dir, no entra a qüestionar-se-la ${ }^{12}$, sinó que el que fa és intentar forçar una explicació que entri en la definició (torn 16: indica que quieres algo $\downarrow$ a lo mejor a veces es una acción involuntaria pero es una acción $\downarrow$; torn 18: sí $\downarrow$ bueno es una: reacción pero sí $\downarrow$ es una acción que hace $\downarrow$ ).

Tot $\mathrm{i}$ això, veiem clarament que no és el significat d'acció el que l'ajuda a reconèixer el verb, ja que d'una banda identifica verbs que no són d'acció, i d'una altra no considera amenaza com a verb tot i la petita "trampa" que li posa l'entrevistadora. Quan li pregunta directament com reconeix el verb, l'alumna mostra l'estratègia que fa servir per saber si una paraula és o no és un verb: buscar-ne l'infinitiu.

Les entrevistes aporten dades molt significatives que ajuden a aprofundir en les representació que han construït de la categoria, d'altra banda molt complexa i plena de matisos. Per exemple, han desenvolupat algunes estratègies generals per reconèixer el verb (buscar-ne l'infinitiu, conjugar la paraula, que indiqui acció, que aporti la idea de temporalitat, que tingui una forma determinada, etc.) que els permet identificar la categoria i que contrasten en cada ocasió amb altres sabers "intuïtius". Ara bé, no sempre és reeixida perquè no la tenen sistematitzada, com si els aspectes enunciats en els sabers declaratius no s'haguessin construïts sobre una base sòlida, la qual cosa no els permet crear la noció global.

\section{Conclusions}

De l'anàlisi de resultats de les diverses activitats i especialment de les entrevistes, se'n desprenen algunes conclusions. Els alumnes distingeixen amb facilitat la categoria verb, però també evidencien que no l'han interioritzat i no entenen molts dels aspectes que utilitzen per definir-lo. Fan servir definicions nocionals incompletes, confonen conceptes i, sobretot, detectem que són sabers desconnectats els uns dels altres, com si formessin part de compartiments estancs. La representació de la categoria que han creat es sustenta en una barreja de sabers intuïtius i sabers escolars que a vegades entren en contradicció, però que formen les idees prèvies d'aquests alumnes sobre el verb, idees 
fortament consolidades i que costa desautomatitzar (com la definició de verb com a paraula que expressa acció; l'associació automàtica i simplista de les formes compostes amb dos verbs junts, etc.).

Hi ha una separació entre uns sabers declaratius - memorístics, poc sistematitzats- $\mathrm{i}$ els procediments que fan servir per identificar la categoria $i$ que activen de manera aleatòria. Com en el cas d'altres recerques (Notario, 2000), constatem la força dels exemples -sovint prototípics i simplificadors- a l'hora de conceptualitzar la categoria. Fer senzilla la complexitat, però, no permet als alumnes entendre-la millor.

D'especial dificultat és el reconeixement del temps verbal. Els alumnes tenen la representació que la distribució dels diferents temps verbals és aleatòria, que només se sap si s'estudia de memòria, i que tenen noms molt difícils i estranys. En canvi, tenen la idea preconcebuda que és fàcil distingir entre present, passat i futur, per aquesta representació del temps gramatical que es fan a partir d'un eix temporal cronològic que només sembla tenir té tres punts d'intersecció: l'ara, l'abans i el després). És una idea molt rígida de les formes verbals que, en la seva simplificació, els dificulta la possibilitat de sistematitzar el paradigma verbal. Ara bé, quan se'ls posa en situació d'observar i reflexionar al voltant d'aquest aspecte, veiem com hi detecten molts matisos. En el moment en què la investigadora els col·loca en situació d'ordenar unes oracions -és a dir, manipular, experimentar amb el llenguatge- els nois i les noies comencen a veure-hi altres possibilitats; comencen a valorar, en definitiva, la relació entre el sentit i la forma.

També és en el moment en què se'ls activa el raonament metalingüístic quan es fan més evidents les dificultats per parlar de la llengua, ja que els falten les eines fonamentals: els fallen les paraules per parlar de l'objecte de saber. La manca d'una terminologia específica és un símptoma de la manca de sistematització dels seus coneixements sobre la llengua, però alhora n'és la causa: no poden fer una abstracció d'allò que no saben com anomenar. Per això, sovint intenten apropar-s'hi des d'un llenguatge comú.

Les entrevistes posen de relleu el pobre paper que la reflexió té en la gramàtica que han après. No estan acostumats a argumentar, ni tampoc a que se'ls pregunti. En canvi, els alumnes es mostren molt actius davant les preguntes -fins i tot podríem dir que molt "motivats" pel repte que els suposen. L'activitat metalingüística que porten a terme en els moments d'interacció amb la investigadora genera unes observacions sobre la llengua que van més enllà de les definicions escolar. 
Des del punt de vista de l'ensenyament, té unes implicacions evidents: cal una metodologia d'aula que parteixi de la representació que han construït els alumnes, que la faci emergir a través de la interacció, i que no defugi la complexitat de l'objecte d'estudi. Cal, per tant, dissenyar activitats d'ensenyament $\mathrm{i}$ aprenentatge que permetin als nois i les noies verbalitzar les representacions que han construït sobre les categories, com a primer pas per poder-los acompanyar en la necessària evolució dels conceptes construïts i que els permeti organitzar d'una manera sistemàtica el seu coneixement sobre la llengua. Les recerques sobre representacions dels estudiants poden ser una aportació per comprendre com aprenen els alumnes i on troben els obstacles, i, per tant, poden donar pistes de com afrontar-los en una situació d'ensenyament i aprenentatge; és a dir, com orientar l'acció didàctica. En aquest procés és necessari expressar les idees -oralment i per escrit-, argumentar-les. Cal, per tant, parlar de gramàtica a l'aula (cfr. Durán 2009a) per construir un coneixement sistemàtic sobre la llengua que es basi en uns fonaments sòlids.

\section{Referències bibliogràfiques}

Brossard, M.; Lambelin, G. (1985): "Problèmes póses par l'acquisition de quelques notions grammaticales". Reveu française de pédagogie, 71, p. 23-28.

Camps, A. (2000a) "El coneixement gramatical dels alumnes: el cas dels pronoms personals" a MACIÀ, J.; SOLÀ, J. (ed.): La terminologia lingüística en l'ensenyament secundari. Propostes pràctiques. Barcelona. Graó.

Camps, A. (2000b). "Aprendre gramàtica" a CAMPS, A.; FERRER, M. (coords.): Gramàtica a l'aula. Barcelona. Graó, p. 101-117.

Camps, A. (2003): Seqüències didàctiques per aprendre gramàtica (SDG), Papers de treball, núm. 1, Departament de Didàctica de la Llengua i la Literatura. Universitat Autònoma de Barcelona.

Camps, A.(coord.) (2005): Bases per a l'ensenyament de la gramàtica. Barcelona. Graó.

Camps, A. (2007): "Actividad metalingüística y aprendizaje de la gramática:hacia un modelo de enseñanza basado en la actividad reflexiva". Cultura y Educación (en premsa).

Camps, A; Guasch, O. Milian, M.; Ribas, T. (2000): "Metalinguistic Activity: the link between writing and learning to write" a CAMPS, A.; MILIAN, M. (eds.): Metalinguistic Activity in Learning to Write. Amsterdam: AUP, 103-124.

Camps, A; Milian, M.; Guasch, O.; Pérez, F.; Ribas, T.; Castelló, M. (2001). "Los conceptos gramaticales de los alumnos de secundaria: el pronombre personal". Dins Camps, A. (coord.) El aula como espacio de investigación y reflexión. Barcelona. Graó, pp. 161-180.

Camps, A; Milian, M. (2000): "La actividad metalingüística en el aprendizaje de la escritura" a Camps, A; Milian, M. (eds.): El papel de la actividad metalingüística en el aprendizaje de la escritura. Rosario. Homo Sapiens, pp. 738. 
Camps, A.; Zayas, F. (2006) Seqüències didàctiques per a aprendre gramàtica. Barcelona. Graó.

Charolles, M.; Combettes, B. (2004): "De la frase al discurs: ruptura i continuïtat" a Articles de Didàctica de la Llengua i la Literatura, núm. 33, p. 79-105. Barcelona. Graó.

Coll, C.; Martin, E.; Mauri, T. i altres (1993): El constructivismo en el aula. Barcelona. Graó.

Cuenca, M.J. (1996): Sintaxi fonamental. Barcelona. Empúries.

Durán, C. (2008): Parlem del verb amb els alumnes de Secundària. Representacions gramaticals i activitat metalingüística. Tesi de Màster. Universitat Autònoma de Barcelona. [en línia] Disponible a: http://www.xtec.es/sgfp/llicencies/200708/memories/1770m.pdf

Durán, C. (2009a): "Hablar, escuchar y pensar para aprender gramática". Cuadernos de Pedagogía, 391 [en premsa].

Durán, C. (2009b): "Parlem de l'adverbi: els conceptes gramaticals dels alumnes de l'ESO". Articles de Didàctica de la Llengua i la Literatura, 49 [en premsa].

Fisher, C. (1996). "Les savoirs grammaticaux des élèves du primaire: le cas de l'adjectif'. Dins Chartrand, S.: Pour un nouvel enseignement de la Grammaire. Montreal (Québec). Ed. Logiques, p. 315-340.

Fisher, C. (2004): "La place des représentations des apprenants en didactique de la grammaire", a VARGAS, C. (dir.): Langue et études de la langue. Approches linguistiques et didactiques (p. 383-393). Aix-en-Provence. Publications de l'Université de Provence.

Fittipaldi, M. (en premsa): "Los sujetos frente a la complejidad. Un acercamiento a las representaciones gramaticales sobre el adverbio de los alumnos de ESO. Textos.

Fontich, X. (2006). Hablar y escribir para aprender gramática. Barcelona. ICEHorsori.

Kilcher-Hagedorn, H.; Othenin-Girard, C.; Weck, G. de (1987): Le savoirs grammatical des élèves. Berne. Peter Lang.

Lantolf, J.; Appel, G. (1994). "Theorical Framework: An Introduction to Vygotskyan Approaches to Second Language Research" Dins de Lantolf, J.; Appel, G. (ed.) Vygotskyan Approaches to Second Language Research. New Jersey Publishing Corporation.

Lantolf, J. (2000): "Introducing sociocultural theory" dins de Lantolf, J. (ed.) Sociocultural Theory and Second Language Learning. Oxford University Press.

Milian, M.; Camps, A. (2006): "El razonamiento metalingüístico en el marco de secuencias didácticas de gramática (SDG)". Dins de CAMPS, A. (coord.) Diálogo e investigación en las aulas. Barcelona. Graó.

Notario, G. (2000): Conceptos gramaticales en alumnos de $4^{\circ}$ de ESO. El sujeto. Treball d'investigació de $3 \mathrm{r}$ cicle. Universitat Autònoma de Barcelona. Treball no publicat.

Notario, G. (2001). "Los conceptos gramaticales de los alumnos de secundaria: el sujeto". Dins CAMPS, A. (coord.) El aula como espacio de investigación y reflexión. Barcelona. Graó, pp. 181-193.

Vigotski, L.S. (1988): Pensament i llenguatge. Vic. Eumo Editorial/Diputació de Barcelona. 
Referència de l'autora:

Carme Durán Rivas és llicenciada en Filologia Hispànica i Màster en Recerca en Didàctica de la Llengua i la Literatura, i és professora de secundària i professora associada del Departament de Didàctica de la Llengua i la Literatura de la Universitat Autònoma de Barcelona (UAB). Les seves principals àrees de recerca són la reflexió metalingüística i la didàctica de la gramàtica, i l'ús de les noves tecnologies en l'ensenyament $\mathrm{i}$ aprenentatge de la llengua i la literatura, sobre les quals ha fet diverses publicacions. Pertany al grup GREAL (Grup de Recerca en Ensenyament i Aprenentatge de Llengües), dirigit per la Dra. Anna Camps. A més del seu treball acadèmic, és formadora del professorat del Departament d'Educació de la Generalitat de Catalunya en el programa de Pràctica Reflexiva i el de Llengües i TIC. carme.duran@uab.cat

\footnotetext{
${ }^{1}$ Aquest treball forma part d'un projecte de recerca que l'autora ha desenvolupat gràcies a una llicència retribuïda concedida pel Departament d'Educació de la Generalitat de Catalunya (DOGC núm. 4968 de 14.09.2007). Es pot consultar a http://www.xtec.es/sgfp/llicencies/200708/memories/1770m.pdf

${ }^{2} \mathrm{D}$ 'entre aquestes propostes, en destaquem les seqüències didàctiques per aprendre gramàtica $(\mathrm{SDG})$ desenvolupades a Camps (2003 i 2005) i a Camps i Zayas (2006).

${ }^{3}$ Grup de Recerca sobre l'Ensenyament i l'Aprenentatge de Llengües del Departament de Didàctica de la Llengua i la Literatura de la Universitat Autònoma de Barcelona, dirigit per Anna Camps.

${ }^{4}$ Les entrevistes han estat transcrites segons la proposta de codis de transcripció utilitzada pel Cercle d'Anàlisi del Discurs de la Universitat Autònoma de Barcelona, que parteix d'una adaptació del nivell intermedi que propugna Payrató (1995).

${ }^{5} \mathrm{Si}$ comparem aquests resultats amb els d'altres recerques sobre representacions gramaticals dels alumnes de l'ESO, veurem que el percentatge de verbs identificats és molt superior al d'altres categories. Per exemple, en els treballs de Durán (2007) i Fittipaldi (2007) sobre l'adverbi, el percentatge de reconeixement només és d'un 32\% i un 36\% respectivament. De l'estudi de Macià (2008) també se'n desprèn que hi ha categories més "fàcils" d'identificar que altres, com és el cas del nom, mentre que l'adverbi torna a aparèixer com una de les menys identificades pels alumnes.

${ }^{6}$ En el cas de les formes no personals, el límit entre una categoria i l'altra (verb-adverbi i verb-adjectiu) és poc clar. Alguns lingüistes fins i tot no consideren el participi com a forma verbal.

${ }^{7}$ Ens referim al que alguns autors anomenen el cotext; és a dir, al conjunt d'elements lingüístics que els estudiants troben al voltant del verb en el text que servia de base per a l'activitat.

${ }^{8}$ En el cas de l'auxiliar, creiem que el fet que siguin cíclits verbals, és a dir, que no tenen la càrrega lèxica i depenen sintàcticament de l'altra forma verbal que aporta el significat, fa que no el tinguin en compte a l'hora de subratllar-lo. És a dir, que sembla que el que preval és el valor semàntic. Ara bé, és curiós que un nombre elevat d'alumnes, que en algun cas arriba fins al 37\%, detecta només els participis de les formes compostes i els identifica com a verb i, en canvi, no l'han identificat com a verb quan anava sol. Això ens fa pensar que, tot i que no hagin subratllat l'auxiliar, d'una manera implícita han tingut en compte la informació gramatical que hi aporta

${ }^{9}$ Pensem que això explicaria per què, per exemple, un $13 \%$ dels alumnes considera que el gerundi és present, en una aproximació intuïtiva a la idea de simultaneïtat amb el verb principal.

${ }^{10}$ Algunes investigacions s'han centrat en les diferències evidents entre llenguatge comú i llenguatge específic i les diferents habilitats que es necessiten per desenvolupar ambdós tipus de llenguatge (Snow, 1987; Wong Filmore, 1982; citats a McLaughlin, 2006: Mitos y falsas creencias acerca del aprendizaje de una segunda lengua: lo que todo profesor debería olvidar. Textos de Didáctica de la Lengua y de la Literatura, 41, p. 71-83. Barcelona.) McLaughlin també aporta dades d'una recerca de Cummins (1980) en què mostra la dificultat que suposa el domini d'apectes més específics i descontextualitzats de la llengua als nens immigrants, tot i que aparentin tenir un bon domini de l'oral. Aquesta distinció entre llenguatge comú i llenguatge científic pren com a punt de referència la distinció vigotskiana entre conceptes espontanis i conceptes científics, amb un origen i desenvolupament diferents en l'ésser humà, però amb molts punts en comú (cfr. Vigotski, 1994).

${ }^{11}$ Altres aspectes en què aprofundim en el treball de recerca en què ens basem per a la redacció d'aquest article (Durán 2008) són: el verb com a expressió de temporalitat, la distinció entre formes simples i compostes, la concordança verbal, la sistematització del temps verbal i les representacions sobre l'ensenyament $\mathrm{i}$ aprenentatge de la gramàtica que tenen els alumnes entrevistats.
} 
${ }^{12}$ Veiem que li costa acceptar que la idea prèvia que té sobre el verb és equivocada; és a dir, que el saber declaratiu que ha construit sobre el verb es converteix en una paret amb la qual s'ha d'enfrontar qualsevol idea nova. 